\title{
Programmes design for teachers' professional development as a way of organizational development for the human's capital of the university
}

\author{
Rimma Gilmeeva, Liutsiia Shibankova* \\ Laboratory «Cognitive pedagogy and digitalization of Education», Institute of Pedagogy, Psychology \\ and Social Problems, 420039 Isaev Str., Kazan, Russia
}

\begin{abstract}
The relevance of the article is caused due to the importance of teacher's professionalism in achieving success of university's educational activity, and quality of higher education which defines the need for teacher's continuous professional growth in higher school according to the pedagogical career strategy. It is determined by teacher's individual needs and abilities, as well as the inquiries of the university. The leading role in the complex of training materials for additional professional education belongs to additional programmes of teachers' professional development. The purpose of the article is to design additional programmes for teachers' professional development and to identify the criteria for their efficiency. Packages of modular-based programmes, stages for design of the program for teachers' professional development, characteristics of modular-based educational programmes, groups of quality criteria for the additional program for teachers' professional development and a matrix of an expert assessment of programmes for teachers' professional development (online mode) within external expertise are presented in the article. The authors emphasize the special role of personnel's potential in the system of additional professional education. The article is intended for scientists, teachers, experts of the system of additional professional education, postgraduate students and students.
\end{abstract}

\section{Introduction}

Recognition of knowledge as the main powerful engine of progress and its great, international value sets the tasks, the positive solutions of which will contribute to the step-by-step development of the state, in general and education, in particular. Training specialists in higher education organizations has to meet some of the requirements, which are international, and are corresponding to the conditions assigned to education by the new system of the international organization and the system of economy [1]. On the background of the highest stage of a postindustrial era and the fourth technological revolution, the significant changes occurred in the education systems of different countries. At the same time, it is important to note that the human

\footnotetext{
${ }^{*}$ Corresponding author: 1uz7@yandex.ru
} 
capital has always been "a major factor for the changes of economy and society types (the accumulated knowledge, intelligence, innovations, professionals)" [2].

The significant changes caused by digital transformation of education [3], the fast-forward technological development, formation of the global educational environment suggest opportunities to possess collectively knowledge, technologies, social values and also to comprehend developmental, cross-country trends in higher education (regionalization, internal integration, etc.) $[4,5]$. They are constantly preserving two main positions of an education system: the quality of higher education as the key parameter and a role of the teacher as the defining factor of an educational process $[6,7]$.

Success and efficiency of educational organization' $s$ functioning in higher education, compliance to constantly changing requirements of education both at the international level and at the level of the state, and achievement of the main objective - training for all spheres of new economy, are defined, first of all, by the activities of university's pedagogical personnel. Pedagogical employees of the university, their hard-, soft- and self-competences, their personal values and settings comprise the special value of the university and shape its human capital [8].

In modern conditions the University-teacher has to take into consideration developmental trends of the modern society, satisfy the requirements of an education system, keep on being upto-date. It defines need for teacher's constant self-improvement and increase in level of the professionalism of the higher school [9].

Today the role of innovations, adaptability of education to the undertaken reforms (in details presented in national projects of the Russian Federation "Science" and "Education"), the need for significant updating the content of the programmes for teachers' professional development in higher school is emphasized. Thus, having solved a problem of teacher's professional growth, it is possible to realize human's continuous enhancing of competences and knowledge throughout all his (her) educational and professional life activities [10,11].

\section{Materials and methods of research}

The teacher's continuous professional growth in higher schools is carried out in accordance with pedagogical career strategy which is defined by teacher's individual needs and abilities as well as the inquiries of the university, where the teacher performs his (her) professional activity, in particular and also an education system, in general. Formation of teacher's career strategy in the university is caused by the inter-connected directions of teacher's professional development: individual growth (increase in potential of the personality, self-education of certain qualities); pedagogical mastery (the highest indicator of teacher's professional activity); scientific growth (as a result of the decision-making, realized by the teacher in higher school on independent scientific tasks); status growth of the teacher (change of the official status of the teacher, his(her) social role). Variable opportunities of teachers' career strategies, and their professional growth in any suggested direction are boundless. The development of career strategies, the successful implementation of programmes for teachers' professional development, the choice of effective forms, methods of teachers' professional development should be regulated by the university $[9,12,13]$.

The vectors of teachers' professional growth are flexible; they reflect the complicated and dynamic nature of teacher's professional activity, variety of defined points, a set of stages for teachers' professional growth, increasing the "hard" and "soft" competences of the teacher in higher school. A great variety of individual strategies of University-teacher's professional growth implies the need of a wide range of various additional programmes for their professional development in higher school.

An integrated individual construct is the package of additional educational programmes of teachers' professional development. Packages of educational programmes are aimed at a certain 
level of teachers' professional development, the usage level of which depends on teachers' education, experience of pedagogical activity, experience in the higher educational organization:

- package for programmes of teachers' professional development ("Beginner" level); level);

- package for programmes of teachers' professional development ("Candidate for Master"

- package for programmes of teachers' professional development ("Master" level);

- package for programmes of teachers' professional development ("Researcher" level).

At each level of functioning the programmes for teachers' professional development, in the presence of more prepared and skilled category of pedagogical personnel, "the plus" program position is defined. Within a package, the logical sequence, continuity, logicality of carefully designed programmes for teachers' professional development are obligatory to achieve. Therefore, the questions on design and identification of criteria for evaluation the efficiency of additional educational programmes for teachers' professional development are kept being significant and relevant.

In the following research, these theoretical methods were used: the analysis and synthesis of scientific works on a research subject, generalization, comparison and systematization of the received results. The methods of pedagogical design and modeling of pedagogical situations; methods of questioning, pedagogical expertise, pedagogical monitoring, statistic data processing were used, as well.

\section{Results}

In the sphere of additional professional education, different forms of teachers' professional development exist, complimenting each other: for example, a training of teachers of the educational organization at the profile enterprise or trainers' professional development in the process of realization of dual training by the educational organization [14]. At the same time, one of the key aspects of the organization of additional professional education is the development of additional programmes for teachers' professional development, along with certification of pedagogical personnel and creation a system of forecasting personnel's requirements of the educational organization.

In the complex of training materials for additional professional education, the programmes of teachers' professional development occupy the leading position. It is connected with the distinctive characteristics inherent to an educational program of this kind, such as: goal-centered focus of an educational process; diagnostics of goal-setting; cyclic nature of training process; fast-forward feedback.

Putting emphasis on the quality of educational resources, we emphasize the need of careful work on each design stages of the program for teachers' professional development. First of all, it deals with the analysis of a new type of activity for the course listeners of the educational program. Applying to the results of this analysis, it is possible to design the content of training. Special attention is paid to the deliberate choice and a complex of methods, forms and means of training and self-training, to design of the didactic materials and planning of an independent work. The last and one of the most significant stages in the design of the additional professional program is development of materials for checking up and assessment of results of listeners' training on the additional professional program [15].

Practice and results of organizations' and institutions' activity on implementing programmes for additional professional development reveal the need of further enhancing of the pedagogical process, the quality of training, achievement of students' independence within an advanced training course, and an individualization of teaching content. The successful solution of these tasks demands application of modular-based additional professional programmes. The modular-based programmes provide the flexibility of training, adopting them according to the listeners' individual needs, and the level of their 
(professional) pedagogical training. The positive characteristics of modular-based programmes for teachers' professional development are as follows: a possibility of structuring the content of training on the separated elements; flexibility of the program; dynamism; efficiency and resultativity; consciousness of perspectives.

Further, we consider that it's necessary to emphasize the dependence of quality of programmes implementation on supplementation with the training materials at the sufficient level, revealing aspects of the content of the designed educational program for teachers' professional development. Therefore, their insufficiency causes subjectivity in the content of the program for teachers' professional development. At the same time, the congestion of program contents with materials of minor character should be avoided. The relevance, in this case, serves as a prerequisite of demand of the designed additional professional program.

The obligatory invariant module for all levels and positions of packages is the module containing contents of "novels" of the state educational policy, instruments of their realization, features of educational policy at the regional and municipal level; relevant acts and practical actions in the format of priority federal projects; Russian and foreign "novels", containing innovative pedagogical practices.

Further comes the variety of modules, depending on a vector of teacher's professional growth: the modules are focused on enhancing soft-and hard-competences for development of a pedagogical mastery, an individual growth, a scientific growth and a status growth. At the same time, the modules do not have the static position. Applying to an individual vector of teacher's professional development, the change of a position of any presented educational module is possible, while the system of credit and test units will allow you to avoid risk of module repeting in an educational program [9].

In realization of additional professional programmes, special attention is paid to the question of personnel's potential in a system of additional professional education, preparation and formation of the pedagogical core according to competence-based model of the modern teacher who is a specialist in andragogy. This kind of teacher is ready and has an ability for a constant change of the teaching "repertoire" (teaching style), to choose and mixture of forms, methods and technologies of training, coherent to the purposes and tasks of the additional professional program of a certain level and a position.

The packages of educational programmes are implemented via means of corresponding forms, methods and technologies. A modern reality in the sphere of post-degree education together with the challenges of time implies development and application in educational process of the sufficient methods, technologies of training and forms of the organization of training providing enhancing of teachers' professional development. Implementation of the program has to correspond to the andragogy ideas and answer expectations of the teachers in the process of teachers' professional development. In general, the deliberate choice of a method depends on the content of education, and is defined by the strategy of training, and is internally motivated by the type of interaction between a teacher and the audience [16].

In our case, the content of additional professional programmes is defined by the individual road map of teacher's professional growth on training personnel. Each of the main strategies of teachers' training implies the deliberate choice of prevailing technologies and methods in order to achieve the training objective within the most rational use of educational resources, and defining forms of the organization of educational process and the productive mode of training.

The deliberate choice of a form for the training organization is caused by the type of interaction between a teacher of an additional education and the course listeners (students). Having chosen as criterion a way of communication between the teacher-trainer and the teacher-trainee, who are in the process of their teachers' professional development, these methods can be classified as follows: 
- training methods by means of interaction of the trainee with educational resources (self-training of the teacher in higher school);

- methods of the individualized training and learning (training in the mode "one to one");

- methods which are based on the using a training material in the mode "one to many" is (for example, an electronic lecture);

- methods which are characterized by an active interaction between all participants of an educational process (the mode "many to many").

Thus, it is worth noting, that the success of pedagogical activity of the teacher on training the pedagogical personnel depends on a sufficient choice of the purpose and the strategy of training, understanding of features and an ability to compliment any presented methods and forms of education.

Additional professional programmes, being a part of a system of higher school teachers' professional growth, provide realization of an individual career strategy for teachers' professional growth, while interacting with multi-functional educational environment.

Speaking about the criteria of efficiency of additional programmes for teachers' professional development, it should be noted that the main criterion for evaluation of the educational program is defined by the Federal law "About Education in the Russian Federation". The additional educational program has to provide enhancing and/or formation of new competences which are necessary for higher school teachers' professional activity [17] which is a main objective of the program for teachers' professional development. It is possible to achieve, if the educational program corresponds to criteria on the standard, substantial and technological levels. Quality criteria of the additional professional program comprise the following groups of criteria.

The normative group of criteria assumes: compliance of content, structure of additional professional programmes (modules) to federal, regional regulatory requirements; compliance to qualification requirements to the professions and positions.

Compliance to criteria of substantial group assumes: relevance and demand of the additional professional program, compliance to the purposes and problems of transformation of education at the present stage in the era of digitalization; coherence of the following criteria: the purpose, the subject of the program, its content, the planned results of training, the conditions of realization, the forms of checking up and the means of assessment; the integrity of the program including invariant and variable parts in the form of thematic modules; program scientific and methodological support.

Technological group of criteria assumes: compliance to modern educational technologies, methods, forms of organization the process of training and means of training; an implementation of modern information technologies for ensuring personality- oriented nature of training; presence of the research, design and practice-oriented kinds of activities; the organizational and pedagogical conditions suggesting an opportunity to design for the individual educational vectors.

In the conditions of a pandemic of Covid-2019 which caused obligatory to preserve an isolation mode, and, respectively, the remote (distance) mode of teachers' work of the educational organizations at all levels implies readiness of an educational and methodological support for the educational process to perform online-activities. All requirements to traditional way of pedagogical process should be observed in online mode. It concerns also additional educational programmes which should be adopted for the course listeners of programmes for teachers' professional development. Therefore, we consider that in modern conditions of educational process the identification of criteria for evaluation an efficiency of distance learning in the sphere of additional professional education, and teachers' professional development is necessary. 
In the process of our research, more than 20 programmes for teachers' professional development were analyzed in the framework of additional professional education; the results of their realization within pedagogical groups were also studied.

In the process of assessing the implementation of educational programmes for additional professional education in an online mode, there was done an expertise on deliberate choice while realizing of educational opportunities for the purpose of obtaining complete information. During this process the following aspects should be analyzed: program for teachers' professional development; videos of the studies that were realized in distance education; reporting materials of the project (results of course listeners', teachers', course organizers' questionnaires; results of pedagogical monitoring; results of performance of individual tasks by course listeners). The presented materials allow us to carry out an expertise with high level of reliability via means of flexible complex of self-audit and external audit in the efficiency assessment. The assessing criteria, presented in Table 1, comprise the problem-based structure of the expertise.

Table 1. Criteria for an expertise on realization of additional professional education (teachers' professional development)

\begin{tabular}{|c|l|}
\hline $\begin{array}{c}\text { The number } \\
\text { of criteria }\end{array}$ & \multicolumn{1}{c|}{ The content of criteria } \\
\hline 1 & compliance of the project to the regulatory documents \\
\hline 2 & $\begin{array}{l}\text { compliance of the content of training to the objective of prevention professional } \\
\text { "burning out" }\end{array}$ \\
\hline 3 & $\begin{array}{l}\text { realization of the variability and-level differentiated principles of educational process } \\
\text { as a condition for providing high-quality service }\end{array}$ \\
\hline 4 & identification and differentiation of course listeners' need \\
\hline 5 & $\begin{array}{l}\text { ensuring availability and mobility of training within special conditions of educational } \\
\text { process (a pandemic of Covid-2019) }\end{array}$ \\
\hline 6 & $\begin{array}{l}\text { implementation of modern information technologies for ensuring the personality- } \\
\text { oriented and variable nature of educational process in the course of teachers' } \\
\text { professional development }\end{array}$ \\
\hline 7 & $\begin{array}{l}\text { realization of the practice-oriented activity in the course of teachers' professional } \\
\text { development }\end{array}$ \\
\hline 8 & $\begin{array}{l}\text { educational and methodological support for the program of teachers' professional } \\
\text { development }\end{array}$ \\
\hline 9 & $\begin{array}{l}\text { psychologic and pedagogical support of the course listeners of teachers' professional } \\
\text { development }\end{array}$ \\
\hline 10 & presence of diagnostic instruments for assessing the results of training \\
\hline 11 & presence of the reporting materials on efficiency of educational process \\
\hline
\end{tabular}

The analysis of the mentioned above meaningful directions of expertise was carried out on the basis of synthesis three main functions of monitoring procedures:

- stating procedure (identification of purpose, and a resource basis, as well as the implemented, organizational mechanisms for realization of the tasks connected with providing opportunities of high-quality teachers' professional development on obtaining new knowledge and skills);

- adjusting procedure (identification of the drawbacks, risks, contradictions and conflicts connected with implementation of the tasks);

- forecasting procedure (accumulation and conceptual synthesis of information allowing to reveal the most efficient and perspective means of ensuring possibilities of receiving highquality teachers' professional development).

We offered a matrix for an expert assessment on programmes of additional professional education (Table 2) in the conditions of online-training. It is supposed that several independent experts (at least 3 experts) should evaluate the presented materials in accordance with a 5-grade 
scale in (1 - lack of criterion; 2-insufficient level; 3 - adoptive level; 4 - high level; 5 premium level) with final calculation of an average score.

Table 2. Matrix of an expert assessment the programmes for additional professional education (teachers' professional development (online mode) within an external expertise.

\begin{tabular}{|c|c|c|c|c|c|c|c|}
\hline \multirow{2}{*}{$\begin{array}{l}\text { The } \\
\text { number } \\
\text { of } \\
\text { criteria }\end{array}$} & \multicolumn{5}{|c|}{$\begin{array}{l}\text { The experts' } \\
\text { evaluation }\end{array}$} & \multirow[t]{2}{*}{$\begin{array}{l}\text { An } \\
\text { average } \\
\text { value }\end{array}$} & \multirow{2}{*}{ A resume } \\
\hline & 1 & 2 & 3 & 4 & 5 & & \\
\hline 1 & & & & & & & $\begin{array}{l}\text { Corresponds / corresponds partially / does not correspond to } \\
\text { the regulatory basis of teachers' professional development }\end{array}$ \\
\hline 2 & & & & & & & $\begin{array}{l}\text { Educational content corresponds / corresponds partially / does } \\
\text { not correspond to the modern level of science and pedagogical } \\
\text { practice development }\end{array}$ \\
\hline 3 & & & & & & & $\begin{array}{l}\text { The program for teachers' professional development assumes / } \\
\text { assumes partially / does not assume variability of training, } \\
\text { differentiation of educational processes, modular-based } \\
\text { organization and an individual vector of course listeners' } \\
\text { training }\end{array}$ \\
\hline 4 & & & & & & & $\begin{array}{l}\text { In the framework of additional professional education, the } \\
\text { educational needs, and psychological and pedagogical } \\
\text { difficulties of the course listeners are determined / determined } \\
\text { partially/ are not determined in the professional activity }\end{array}$ \\
\hline 5 & & & & & & & $\begin{array}{l}\text { Providing / providing partially / absence of providing } \\
\text { availability and mobility for target audience in the conditions } \\
\text { of a pandemic Covid - } 2019\end{array}$ \\
\hline 6 & & & & & & & $\begin{array}{l}\text { In the course of the training organization modern, digital } \\
\text { technologies for implementation of pedagogical } \\
\text { communication in a remote (distance) format } \\
\text { are used / are used partially / are not used }\end{array}$ \\
\hline 7 & & & & & & & $\begin{array}{l}\text { An activity of course listeners possesses / possesses partially / } \\
\text { doesn't possess practice-oriented (professional) focus in the } \\
\text { course of training }\end{array}$ \\
\hline 8 & & & & & & & $\begin{array}{l}\text { The educational-methodological support of the program for } \\
\text { teachers' professional development is presented at a high level } \\
\text { / is presented partially / is not presented }\end{array}$ \\
\hline 9 & & & & & & & $\begin{array}{l}\text { Psychological and pedagogical support of the course listeners } \\
\text { is carried out continuously and differentially in a complete } \\
\text { mode / is carried out partially / is not carried out }\end{array}$ \\
\hline 10 & & & & & & & $\begin{array}{l}\text { Diagnostic instruments for assessing the results of training } \\
\text { meet all pedagogical requirements, can be correlated to } \\
\text { qualification requirements / can be extended because of the } \\
\text { description of competences / can't be correlated to the } \\
\text { teacher's professional functions }\end{array}$ \\
\hline 11 & & & & & & & $\begin{array}{l}\text { The reporting materials on efficiency are submitted in a } \\
\text { complete volume / are submitted in sufficient volume /are not } \\
\text { submitted in sufficient volume from all participants }\end{array}$ \\
\hline
\end{tabular}

The presented criteria were repeatedly checked at the expertise of efficiency on additional programmes for teachers' professional development for pedagogical personnel in 2020, and proved their reliability and validity.

\section{Conclusions}


1. Programmes for teachers' professional development in the system of additional professional education suggest an opportunity to response rapidly to the challenges of time, and developmental trends in higher education. They are capable to act as the "drivers" for developing the system of teacher's professional growth in higher school, forming teacher's readiness to the new formats and modes of their professional activity in the era of digitalization.

2. A huge variety of individual strategies for teachers' professional development in higher school implies the same variety of additional programmes for teachers' professional development that demands the thorough programme structuring for teachers' professional development in certain packages at different levels and a careful stage-by-stage design of an educational program. Consequently, modern reality in the sphere of post-degree education, continuous professional education together with the challenges of time (digitalization, globalization, the fast-forward technological development, external integration and Life Long Learning (LLL) imply the design and application the efficient programmes of teachers' professional development in educational setting. It assumes the implementation of sufficient technologies of training and corresponding forms of the organization of process of training. Well-designed, modular-based programmes for teachers' professional development will satisfy the quality criteria for an additional professional program.

3. Modern conditions for education development (positive conditions: digital transformation, artificial intelligence, etc., and negative conditions: a pandemic of Covid2019) implies readiness of an educational and methodological support of the educational process to perform online-activities. The presented matrix of expert assessment for programms of additional professional education on teachers' professional development (online mode) can be transferred to any programmes of additional professional education. It can be realized both at the stage on analysis the efficiency of implementation the program of teachers' professional development, and what is even more important, at a stage for design of the educational program.

4. The quality of teaching activity is provided by the teacher with appropriate level of professional and intellectual knowledge with a scientific nature, and who is possessing the appropriate level of psychological and pedagogical, and methodical training. Efficient teaching activity assumes a teacher's ability to create a psychological and pedagogical interaction both with course listeners and colleagues; to participate in the research / experimental projects; to realize teachers' desire and aspiration to innovations. These are factors defining pedagogical mastery. By increasing the level of professionalism and enhancing the competences, the teacher is able to create a clear algorithm for formation learners' competences which influence on the increase of the education quality in higher school.

\section{References}

1. E. Yu. Levina, R. Kh. Gilmeeva, L. A. Shibankova, Pedagogika, 7(84). 91 (2020)

2. Yu. A. Korchagin, Cycles of human capital development as drivers of innovation waves (CIRE, Voronezh, 2010)

3. A. Yu. Uvarov, I. D. Frumin, Difficulties and prospects of digital transformation of education (Higher School of Economics, Moscow, 2019)

4. R. Kh. Gilmeeva, A. R. Kamaleeva, A. S. Cats, E. Yu. Levina, V. Sh. Maslennikova, L. Yu. L. Mukhametzyanova, T. M. Tregubova, L.A. Shibankova, Cognitive pedagogy (IPPSP, Kazan, 2020)

5. A. M. Korotkov, N. K. Sergeev, IofVSPU, 4(137). 4 (2019)

6. M. Elken, B. Stensaker, QiHE, 3 (24). 189 (2018) 
7. L. Shagrir, TiHE, 8. 783 (2015)

8. L. A. Shibankova, KPJ, 3. 19 (2020)

9. R. Kh. Gilmeeva, E. Yu. Levina, T. M. Tregubova, L.A. Shibankova, Scientific and methodological support of professional growth of a teacher in training (IPPSP, Kazan, 2019)

10. V. E. Kozlov, E. Yu. Levina, S.V. Khusainova, Vestnik CHGPU, 2. 107 (2019)

11. S. Gustavsson, A. Andersén, M. Berglund, RP, 3. 339 (2019)

12. H. Teräs, PDiE, 2(42). 258 (2016)

13. 13. W. Smets, K. Struyven, CE, 1(7). 1742273 (2020)

14. I. I. Falyakhov, KPJ, 2. 45 (2016)

15. T. M. Tregubova, L. A. Shibankova, Russia and the World: the Development of Civilizations (IWC, Moscow, 2018)

16. A.I. Kukuev, Current problems of additional professional education in the south of Russia (IPO PI SFU, Rostov-on-Don, 2008)

17. Federal Law No. 273-FZ of December 12, 2012 "On Education in the Russian Federation". 